ISSN 0122-5383

\title{
KINETIC PARAMETERS DETERMINATION OF FCC GASOLINE HYDROTREATING USING GENETIC ALGORITHMS
}

\author{
DETERMINACIÓN DE PARÁMETROS CINÉTICOS DEL HIDROTRATAMIENTO \\ DE UNA NAFTA DE FCC USANDO ALGORITMOS GENÉTICOS
}

Carlos-Mauricio Celis-Cornejo ${ }^{1}$, Gustavo-Alberto Granados-Zarta ${ }^{1}$, Carlos-Eduardo Bravo-Villarreal' ${ }^{1}$, David de Jesús Pérez-Martínez ${ }^{2}$ and Sonia-A. Giraldo-Duarte ${ }^{1^{*}}$

\author{
'Centro de Investigaciones en Catálisis (CICAT), Escuela de Ingeniería Química, \\ Universidad Industrial de Santander, Bucaramanga, Colombia \\ ${ }^{2}$ ECOPETROL S.A. - Instituto Colombiano del Petróleo (ICP), A.A. 4185 Piedecuesta, Colombia \\ e-mail: sgiraldo@vis.edu.co
}

(Received: Jul. 22, 2013; Accepted: Dec. 05, 2013)

\section{ABSTRACT}

The kinetics parameters for the simultaneous reactions of hydrodesulfurization and hydrogenation of synthetic Fluid Catalytic Cracking (FCC) naphtha over $\mathrm{CoMo} / \gamma-\mathrm{Al}_{2} \mathrm{O}_{3}$ catalyst were determined. The proposed kinetic model considered a Langmuir-Hinshelwood adsorption mechanism (with 16 steps) with just one kind of active site. The amount of experimental data obtained was relatively limited, thus a genetic algorithm accompanied by an optimization through the Nelder-Mead Simplex method were used for the parameter estimations. Trimethylpentenes and 2-methylthiophene were used as representative molecules of unsaturated and sulfur compounds in FCC naphtha respectively. It was possible to calculate kinetic and thermochemical parameters, such as activation energies, adsorption heats and frequency factors with a good enough approach. This methodology results very useful since it allows the parameters determination with accuracy, reducing the amount of experimentation in comparison with traditional methodologies.

Keywords: Hydrodesulfurization, Olefins hydrogenation, $\mathrm{CoMo} / \gamma-\mathrm{Al}_{2} \mathrm{O}_{3}$ catalyst, Stochastic optimization.

How to cite: Celis-Cornejo, C. M., Granados-Zarta, G. A., Bravo-Villarreal, C. E., Pérez-Martínez, D. \& Giraldo-Duarte, S. A. (2013). Kinetic parameters determination of FCC gasoline hydrotreating using genetic algorithms. CT\&F - Ciencia, Tecnología y Futuro, 5(3), 79-94.

*To whom correspondence should be addressed 


\section{RESUMEN}

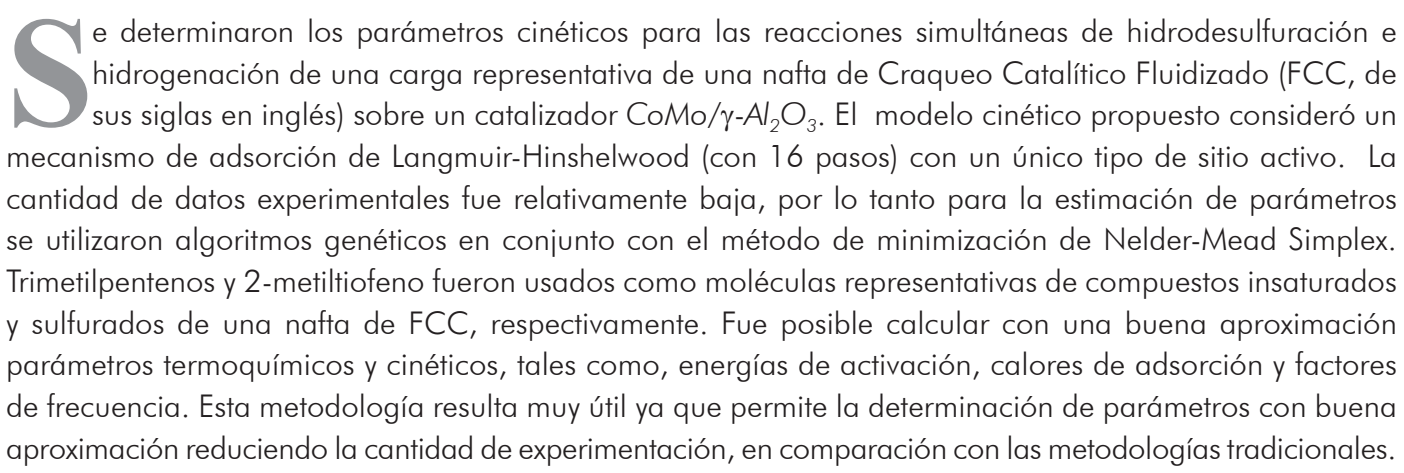

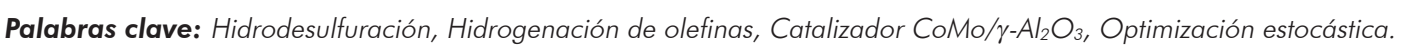

\section{RESUMO}

F oram determinados os parâmetros cinéticos para as reações simultâneas de hidrodessulfuração e hidrogenação de uma carga representativa de uma nafta de Craqueamento Catalítico Fluidizado ( $F C C$, por sua sigla em inglês) sobre um catalisador $\mathrm{CoMo} / \gamma-\mathrm{Al}_{2} \mathrm{O}_{3}$. O modelo cinético proposto considerou um mecanismo de adsorção de Langmuir-Hinshelwood (com 16 passos) com um único tipo de lugar ativo. A quantidade de dados experimentais foi relativamente baixa, portanto, para a estimativa de parâmetros foram utilizados algoritmos genéticos em conjunto com o método de minimização de NelderMead Simplex. Trimetil-pentenos e 2-metil-tiofeno foram usados como moléculas representativas de compostos insaturados e sulfurados de uma nafta de FCC, respectivamente. Foi possível calcular com uma boa aproximação parâmetros termoquímicos e cinéticos, tais como, energias de ativação, calores de adsorção e fatores de frequência. Esta metodologia resulta muito útil já que permite a determinação de parâmetros com boa aproximação reduzindo a quantidade de experimentação, em comparação com as metodologias tradicionais.

Palavras-chave: Hidrodessulfuração, Hidrogenação de olefinas, Catalisador CoMo/ $\gamma-\mathrm{Al}_{2} \mathrm{O}_{3}$, Otimização estocástica. 


\section{INTRODUCTION}

The reduction of pollutants in fuels is nowadays a major challenge in the refining industry due to the increasingly demanding environmental regulations, especially regarding sulfur levels (United States Environmental Protection Agency, 2011). Hydrotreating (HDT) is widely used to remove heteroatoms $(S, N$ and $O$ ) and aromatics contained in petroleum fractions processed in refineries. The development of appropriate catalysts is the keystone to selectively remove those pollutants (Brunet et al., 2005; Ratnasamy \& Sivasanker, 1980; Morterra \& Magnacca, 1996; Pérez-Martínez et al., 2010). Special attention should be placed on the hydrodesulfurization (HDS) of naphtha coming from the Fluid Catalytic Cracking (FCC) unit, which constitutes about $30 \%$ of the gasoline and accounts for 80 to $90 \%$ of the total sulphur content (Song, 2003; Kaufmann et al., 2000).

A considerable amount of olefins are contained in FCC naphtha, and these are largely responsible for its high Research Octane Number (RON). Olefins usually are hydrogenated during the HDS process, thereby, reducing the RON in gasoline. Accordingly, HDS catalysts for FCC gasoline must be selective enough to make deep desulfurization without a significant reduction in the RON (Brunet et al., 2005; Ratnasamy \& Sivasanker, 1980; Morterra \& Magnacca, 1996; Miller et al., 2000). Particularly, HDT catalysts for FCC gasoline must promote the desulfurization reaction instead olefins hydrogenation (HYD), which means to be highly selective for HDS pathway (HDS/HYD). $\mathrm{CoMo} / \gamma-\mathrm{Al}_{2} \mathrm{O}_{3}$ and its modifications are preferred instead of NiMo ones, because of its better HDS/HYD selectivity (Brunet et al., 2005; Ratnasamy \& Sivasanker, 1980; Morterra \& Magnacca, 1996).

A kinetic study of these reactions could be an important contribution since it is necessary to establish reaction mechanisms and notions for reactors design. Furthermore, an adequate and consistent kinetic model allows the determination of kinetic and thermodynamic parameters, which would not be easily measured. Classical nonlinear minimizations methods based on a steepest descent algorithm are commonly used for estimation of thermodynamics and kinetic parameters. Parijis and Froment (1986) studied the kinetics of the tiophene hydrogenolysis using an integral method and Marquardt optimization method as a mathematical tool. Vanrysselberghe and Froment (1996) developed a kinetic model applying a differential method for HDS of dibenzothiophene and a Marquardt routine for the estimation of parameters. Least squares Levenberg-Marquardt method was used in conjunction with the software Origin Lab by Slomkiewicz (2004) in the determination of the kinetic equation for the synthesis of ethers. Vrinat, Laurenti and Geantet (2012) determined kinetic parameters for deep HDS of refractory compounds such as 4,6-dimethyldibenzothiophene (4,6-DMDBT), to understand the inhibition effect of $\mathrm{H}_{2} \mathrm{~S}$ over the metal sulfide species, and the carrier effect on $\mathrm{ReS}_{2}$ catalysts. Jarullah, Mujtaba and Wood (2011) developed kinetics for the HDS of oil using $\mathrm{CoMo} / \gamma-\mathrm{Al}_{2} \mathrm{O}_{3}$ catalysts. They established a system of algebraic differential equations, and solved these employing linear and non-linear approximations for the parameters estimation. Also they propose an optimization method based on the Sum of Squared Error (SSE) minimization, between the experimental and the predicted concentration.

Currently the Transition State Theory (TST) coupled with quantum dynamics calculations has been established as an important methodology for thermodynamics and kinetic parameters estimation, because it is now possible to perform quantum mechanical ab initio calculations without consuming too much computational time and resources (Truhlar, Garrett \& Klippenstein, 1996). However, the implementation of this methodology is still very limited. Daudin et al. (2007), proposed kinetic models for HYD of 2,3-dimethyl-2-butene under the same operational conditions of HDS reactions, by means of the Brønsted-Evans-Polanyi relation. They found a kinetic model that allowed them to raise a rational interpretation of the observed phenomenon. In a later work Daudin et al. (2008) studied the competition between HDS and HYD with model molecules under realistic HDS conditions, over bulk monometallic and bimetallic catalysts. It was considered two simultaneous reactions assuming a unique type of active site in which HDS and HYD compete. The parameters estimation of the kinetics model developed was carried out using again the Brønsted-Evans-Polanyi relation and minimizing the deviation of theoretical HDS and the HYD rates from experimental data, by assuming a Langmuir-Hinshelwood mechanism rate, determining steps and the steady state approximation. 
Some rigorous optimization problems do not converge easily with the gradient-based optimization methods because of their high dimensionality and nonlinearity. The implementation of stochastic methods such as Monte Carlo, simulated annealing and Genetic Algorithms (GAs) are fair options in these cases. The advantage of using GAs instead of gradient-based methods, when mathematical robustness is required, is that GAs have a remarkable balance between exploration and exploitation of the search space, avoiding getting trapped in local minima (Elliott et al., 2004). Abassi and Fetamy (2009) used GAs coupled with a very rigorous mathematical model to search for the optimal conditions in the HDS process of gas oil. The results show that the GAs were used successfully in the process optimization. Farooji, Vatani and Mokhtari (2010) have studied the reaction kinetics of oxidative coupling of methane catalyzed by perovskite, calculating optimized kinetic parameters through the application of genetic algorithms. By comparing the proposed kinetic with the experimental data they obtained an average error of $20 \%$.

In this work, the HDS and the HYD reactions of simulated FCC naphtha feed over a $\mathrm{CoMo} / \gamma-\mathrm{Al}_{2} \mathrm{O}_{3}$ catalyst were studied. The kinetics model proposed by Daudin et al. (2008) was used, applying the LangmuirHinshelwood adsorption mechanisms (Vrinat, 1983). Model parameters were calculated using genetic algorithms. Furthermore, these parameters were enhanced by applying the Nelder-Mead Simplex method (Forrest, 1993; Edgar, Himmelblau \& Lasdon, 2001; MartínezGonzález, 2001; Navidi, 2006; Montgomery \& Runger, 1996). Thermodynamic properties and frequency factors obtained were compared with those reported by Vanrysselberghe and Froment (1996) and Vanrysselberghe, Le Gall and Froment (1998). The latter were statistically validated by calculating confidence intervals, using covariance matrices.

\section{EXPERIMENTAL}

\section{Catalyst Preparation}

CoMo catalyst containing $10.2 \%$ wt of $\mathrm{MoO}_{3}$ and $2.1 \%$ wt of $\mathrm{Co}$, supported on commercial $\gamma-\mathrm{Al}_{2} \mathrm{O}_{3}$ pro- catalyse, was used. $\gamma-\mathrm{Al}_{2} \mathrm{O}_{3}$ (BET surface area: $208 \mathrm{~m}^{2} / \mathrm{g}$, pore volume: $0.6 \mathrm{~cm}^{3} / \mathrm{g}$ and pore diameter: $116 \AA$ ) was modified with $M o$ and $C o$ by incipient wetness impregnation with an aqueous solution of $\left(\mathrm{NH}_{4}\right)_{6} \mathrm{Mo}_{7} \mathrm{O}_{24} \bullet 4 \mathrm{H}_{2} \mathrm{O}$ (Merck, 99\%), and subsequently with an aqueous solution of $\mathrm{Co}\left(\mathrm{NO}_{3}\right)_{2} \cdot 6 \mathrm{H}_{2} \mathrm{O}$ (Sigma-Aldrich, 99.5\%). After each impregnation the solid was dried with $\mathrm{N}_{2}$ flow (100 $\left.\mathrm{mL} \cdot \mathrm{min}^{-1}\right)$ at $120^{\circ} \mathrm{C}$ for $12 \mathrm{~h}$, and then was calcined under air flow $\left(100 \mathrm{~mL} \cdot \mathrm{min}^{-1}\right)$ at $500^{\circ} \mathrm{C}$ for $4 \mathrm{~h}$.

\section{Experimental Procedure}

Catalytic tests were made in a continuous-flow stainless-steel fixed-bed reactor. The catalyst was dried in situ with $N_{2}$ flow $\left(100 \mathrm{~mL} \cdot \mathrm{min}^{-1}\right)$ at $120^{\circ} \mathrm{C}$ for $1 \mathrm{~h}$, followed by the activation at $400^{\circ} \mathrm{C}$ with a $15 \% \mathrm{v} / \mathrm{v}$ of $\mathrm{H}_{2} \mathrm{~S} / \mathrm{H}_{2}$ $\left(100 \mathrm{~mL} \cdot \mathrm{min}^{-1}\right)$ for $3 \mathrm{~h}$. The model feed was conformed of 2-methyltiophene (2MT, Sigma-Aldrich 98\%), as a representative molecule of sulphur compounds, and a mixture of olefins consisting of 2,4,4-trimethylpentene (TMP, Sigma-Aldrich 99\%) diluted in n-heptane (J. T. Baker, 99.4\%) and dodecane (2wt.\%, Sigma-Aldrich $99 \%$ ) as internal standard for chromatographic analysis. The compositions of the model feed are shown in Table 1.

Table1. Model feed concentration for each of the HDS reactions. Each experiment was performed at three temperature levels: 250, 260 and $270{ }^{\circ} \mathrm{C}$.

\begin{tabular}{|c|cc|}
\hline & Concentration of reactant in the charge \\
\hline 1 & 2MT [wt.\%] & TMP [wt.\%] \\
\hline 2 & & 10 \\
\hline 3 & 1.0 & 15 \\
\hline 4 & & 20 \\
\hline 5 & & 10 \\
\hline 6 & & 15 \\
\hline 7 & & 20 \\
\hline 8 & & 10 \\
\hline 9 & 2.0 & 15 \\
\hline
\end{tabular}

2MT: 2-methylthiophene; TMP: 2, 4, 4-trimethylpentene.

The reactor was pressurized with $\mathrm{H}_{2}$ until it reached 1.7 MPa then the liquid load was fed allowing the reac- 
tion to start, at a liquid-flow rate of $20 \mathrm{ml} \cdot \mathrm{h}^{-1}$ and $H_{2}$ to liquid feed ratio of 500. In previous experiments Pérez-Martínez et al. (2010) the absence of any diffusion limitations has been demonstrated, under the mentioned conditions and applying the experiments suggested by Le Page (1987). Liquid samples were taken every hour for about $7 \mathrm{~h}$ of reaction, and these were analysed on a HP 6890 gas chromatograph with a FID detector and a column HP-1 $(100 \mathrm{~m} \times 0.25 \mathrm{~mm}$ $\times 0.5 \mu \mathrm{m})$. Steady state was reached after $3 \mathrm{~h}$ of reaction; this was verified by the stabilization of the total conversion.

Table 1 shows the experimental $3^{\mathrm{K}}(\mathrm{K}=3)$ design used. The concentration of $2 \mathrm{MT}$ and TMP were varied at three levels. Each experiment was carried out at three different temperatures $\left(250,260\right.$ and $\left.270^{\circ} \mathrm{C}\right)$.

The catalytic activity was expressed as the total conversion of the reactants (2MT and TMP) after the steady state was reached.

\section{Mathematical Modeling}

According to the HDS pathway of 2MT proposed by Pérez-Martínez et al. (2010), the 1-pentene, 2-pentene and n-pentene $\left(\mathrm{C} 5_{\mathrm{s}}\right)$ were considered desulfurized products. Although in the HDT of TMP, isomerization and cracking reactions occur at certain extent in order to simplify the kinetic model they were neglected and the direct HYD of TMP reaction producing isooctane was the only one considered as an assumption for the kinetic model.

Table 2 shows the equations that describe the considered mechanisms, corresponding to the reactions of TMP and 2MT respectively (Daudin et al., 2008). For the TMP reactions, the rate determining step is (Equation 5), which is the first hydrogen transferred from the $\mathrm{SH}$ group to the adsorbed TMP. For the $2 \mathrm{MT}$ reaction, the controlling step is Equation 10, which is the first hydrogen transferred to the adsorbed 2MT. Only one type of active site is considered and both reactants are adsorbed competitively. This assumption ought to reduce the degrees of freedom, the mathematical complexity of the model and the number of experiments, without losing reliability in results (Daudin et al., 2008). Thereby, Equations 1 - 5 and Equation 9 are in equilibrium. Equations $6-8$ and Equations 11 - 15 corresponding to desorption and equilibrium for the global system of the reactions, are not taken into account due to these steps and do not contribute to the kinetics model approach. This is because adsorptions in a single active site and the controlling steps have been defined as the relevant criteria for the model (Daudin et al., 2008).

Table 2. Reaction mechanisms for the HYD of TMP and reactions mechanisms for the HDS of $2 \mathrm{MT}$.

\begin{tabular}{|c|c|}
\hline$M^{*}+H_{2} S \stackrel{K_{S}}{\leftrightarrow} M S+H_{2}$ & (1) \\
\hline$M S+M^{*}+H_{2} \stackrel{K_{H_{2}}}{\longleftrightarrow} M S H+M H$ & (2) \\
\hline$M S+M^{*}+H_{2} S \stackrel{K_{H 2 S}}{\longleftrightarrow} 2 M S H$ & (3) \\
\hline$M^{*}+R \stackrel{K_{S}}{\leftrightarrow} M R$ & (4) \\
\hline$M R+M S H \stackrel{K_{S H}}{\longrightarrow} M R H+M S$ & $(5)$ \\
\hline$M R H+M H \rightarrow M R H_{2}+M^{*}$ & (6) \\
\hline $\mathrm{MRH}_{2} \rightarrow \mathrm{RH}_{2}+M^{*}$ & (7) \\
\hline $2 \mathrm{MRH}_{2}+\mathrm{H}_{2} \rightarrow 2 \mathrm{M}^{*}+2 \mathrm{H}_{2} \mathrm{~S}$ & (8) \\
\hline$M^{*}+R S \stackrel{K_{R S}}{\longrightarrow} M R S$ & (9) \\
\hline$M R S+M S H \stackrel{K_{S H}}{\longrightarrow} M R H S+M S$ & (10) \\
\hline$M R H S+M H \rightarrow M R H_{2} S+\mathrm{M}^{*}$ & (11) \\
\hline $\mathrm{MRH}_{2} \mathrm{~S}+\mathrm{MH} \rightarrow \mathrm{MRH}_{3} \mathrm{~S}+\mathrm{M}^{*}$ & $(12)$ \\
\hline $\mathrm{MRH}_{3} \mathrm{~S}+\mathrm{MSH} \rightarrow \mathrm{MRH}_{4} \mathrm{~S}+\mathrm{MS}$ & (13) \\
\hline $\mathrm{MRH}_{4} \mathrm{~S}+\mathrm{H}_{2} \rightarrow \mathrm{MRH}_{4}+\mathrm{H}_{2} \mathrm{~S}$ & (14) \\
\hline $\mathrm{MRH}_{4} \rightarrow \mathrm{RH}_{4}+M^{*}$ & $(15)$ \\
\hline
\end{tabular}

$M^{*}$ corresponds to one adsorption site, $S$ is a Sulphur; the TMP and the 2MT are denoted by $R$ and $R S$ respectively.

The reaction rate equations for HYD and HDS can be expressed as follows (Daudin et al., 2008): 
$r_{H Y D}=k_{H Y D} C_{M R} C_{M S H}$

$r_{H D S}=k_{H D S} C_{M R S} C_{M S H}$

And the sites conservation balance is represented in Equation 18.

$C_{M^{*}}+C_{M R}+C_{M R S}+C_{M S}+C_{M S H}+C_{M H}=1$

Consider Equation 4 in which the first adsorption of TMP occurs. Since this step is in equilibrium, it is valid applying the steady state approximation, so the reaction rate can be written as represented in Equation 19.

$\frac{d C_{M R}}{d t}=k_{R} C_{M^{*}} C_{R}-k_{-R} C_{M R}=0$

Rearranging Equation 19, it is possible to find an expression for the concentration of sites occupied by TMP (CMR) as Equation 20 shows, and this procedure is implemented in all the steps considered in equilibrium. This combined with the Equation 18 leads to an expression for the concentration of metallic sites $\left(\mathrm{M}^{*}\right)$. And, finally, because the reactions are occurring in vapor phase, concentrations can be replaced for partial pressures.

$k_{R} C_{M^{*}} C_{R}=k_{-R} C_{M R}$ with $k_{R}=\frac{k_{R}}{k_{-R}}$

$C_{M R}=k_{R} C_{M^{*}} C_{R}$

Based on these considerations, reaction rate equations for HYD and HDS were obtained (Daudin et al., 2008) and are shown in Equation 21 and Equation 22 respectively.
The terms $k_{H Y D}$ and $k_{H D S}$ are rate constants for the HYD and HDS respectively, depending on the partial pressure and conversions. The latter obeys the Arrhenius law regarding temperature (Vanrysselberghe \& Froment, 1996). $K_{R}$ and $K_{R S}$ are adsorption constants for TMP and 2MT; $K_{\mathrm{H}_{2}}$ and $K_{\mathrm{H}_{2} \mathrm{~S}}$ are equilibrium constants for hydrogen and hydrogen sulphide over the catalytic surface; $K_{S}$ represents the equilibrium constant for the sulphur species. According to Van't Hoff's equation, it is possible to relate adsorption heats with temperature using thermodynamics relations as shown in Equation 23.

$K_{i}=A_{i} \exp \left(-\frac{\Delta H^{0}}{R T}\right)$

The design equation for the fixed-bed reactor (see Equation 24) was used to correlate the experimental results with the model proposed and then obtain model parameters.

$\frac{W}{F_{A 0}}=\int_{x_{1}}^{x_{2}} \frac{d x_{A}}{r_{A}}$

Model parameters were obtained through an optimization strategy shown in Figure 1. As a first step, kinetic parameters reported in literature (Vanrysselberghe \& Froment, 1996) from tiophenic and olefin compounds were taken as initial values to start the calculation. Parameters that fit better and had a lower overall error were used as initial population. Once the initial population and intervals are established, the kinetic parameters were estimated using GAs as implemented in Matlab optimtool GUI. Some characteristic information of the performed GAs is summarized in Table 3.

$$
\begin{aligned}
r_{H Y D}=k_{H Y D} \frac{\left(K_{R} P_{R}\right)\left(K_{H_{2} S} P_{H_{2} S}\right)^{1 / 2}\left(\frac{P_{H_{2} S}}{K_{S}^{\prime} P_{H_{2}}}\right)^{1 / 2}}{\left[1+\left(K_{R} P_{R}\right)+\left(K_{R S} P_{R S}\right)+\left(\frac{P_{H_{2} S}}{K_{S} P_{H_{2}}}\right)+\left(K_{H_{2} S} P_{H_{2} S}\right)^{1 / 2}\left(\frac{P_{H_{2} S}}{K_{S} P_{H_{2}}}\right)^{1 / 2}+\left(K_{H_{2}} P_{H_{2}}\right)\left(K_{H_{2} S} P_{H_{2} S}\right)^{-1 / 2}\left(\frac{P_{H_{2} S}}{K_{S} P_{H_{2}}}\right)^{1 / 2}\right]^{2}} \\
r_{H D S}=k_{H D S} \frac{\left(K_{R S} P_{R S}\right)\left(K_{H_{2} S} P_{H_{2} S}\right)^{1 / 2}\left(\frac{P_{H_{2} S}}{K_{S}^{\prime} P_{H_{2}}}\right)^{1 / 2}}{\left[1+\left(K_{R} P_{R}\right)+\left(K_{R S} P_{R S}\right)+\left(\frac{P_{H_{2} S}}{K_{S} P_{H_{2}}}\right)+\left(K_{H_{2} S} P_{H_{2} S}\right)^{1 / 2}\left(\frac{P_{H_{2} S}}{K_{S} P_{H_{2}}}\right)^{1 / 2}+\left(K_{H_{2}} P_{H_{2}}\right)\left(K_{H_{2} S} P_{H_{2} S}\right)^{-1 / 2}\left(\frac{P_{H_{2} S}}{K_{S} P_{H_{2}}}\right)^{1 / 2}\right]^{2}}
\end{aligned}
$$


Mutation function was chosen as constrain dependent and scattered crossover was used. Some other options as time limit, fitness limit and functions tolerance were set as default. To find the optimal parameters values, a mean square error percentage expressed in Equation 25 was used as the objective function to minimize. This measures the gap between the experimental $W / F_{A 0}$ and the calculated $\left\langle W / F_{A 0}\right\rangle \cdot$ values. $\left\langle W / F_{A 0}\right\rangle$ was calculated through the combination of Equation 24 with Equation 21 and Equation 22. Equation 24 was solved by using Simpson's $1 / 3$ integration method.

$\sum \sum \frac{e_{2 M T^{2}}}{N} * \frac{e_{T M P^{2}}}{N} * 100$

Where,

$e_{2 M T^{2}}=\frac{\left(W / F_{A 0}-\left\langle W / F_{A 0}\right\rangle\right)^{2}}{W / F_{A 0}}$
$e_{T M P}^{2}=\frac{\left(W / F_{A 0}-\left\langle W / F_{A 0}\right\rangle\right)^{2}}{W / F_{A 0}}$

The parameters calculated through GAs were improved using the Nelder-Mead simplex direct search method (fminsearch-Unconstrained nonlinear minimization) minimizing Equation 25, leading to a reduction of the solution range. Both methods were performed sequentially to obtain the objective function global minimum. This strategy was repeated as many times as needed to reduce the solution range for each parameter, and thus minimizing the global error.

Table 3. Characteristic information of used genetic algorithms.

\begin{tabular}{|ll|}
\hline \multicolumn{1}{|c|}{ Parameter } & \multicolumn{1}{c|}{ Value } \\
\hline Population size & 200 \\
\hline Number of generations & 100 \\
\hline Time limit & Infinite (default) \\
\hline Elite count & 2 (default) \\
\hline Crossover fraction & 0.8 (default) \\
\hline
\end{tabular}

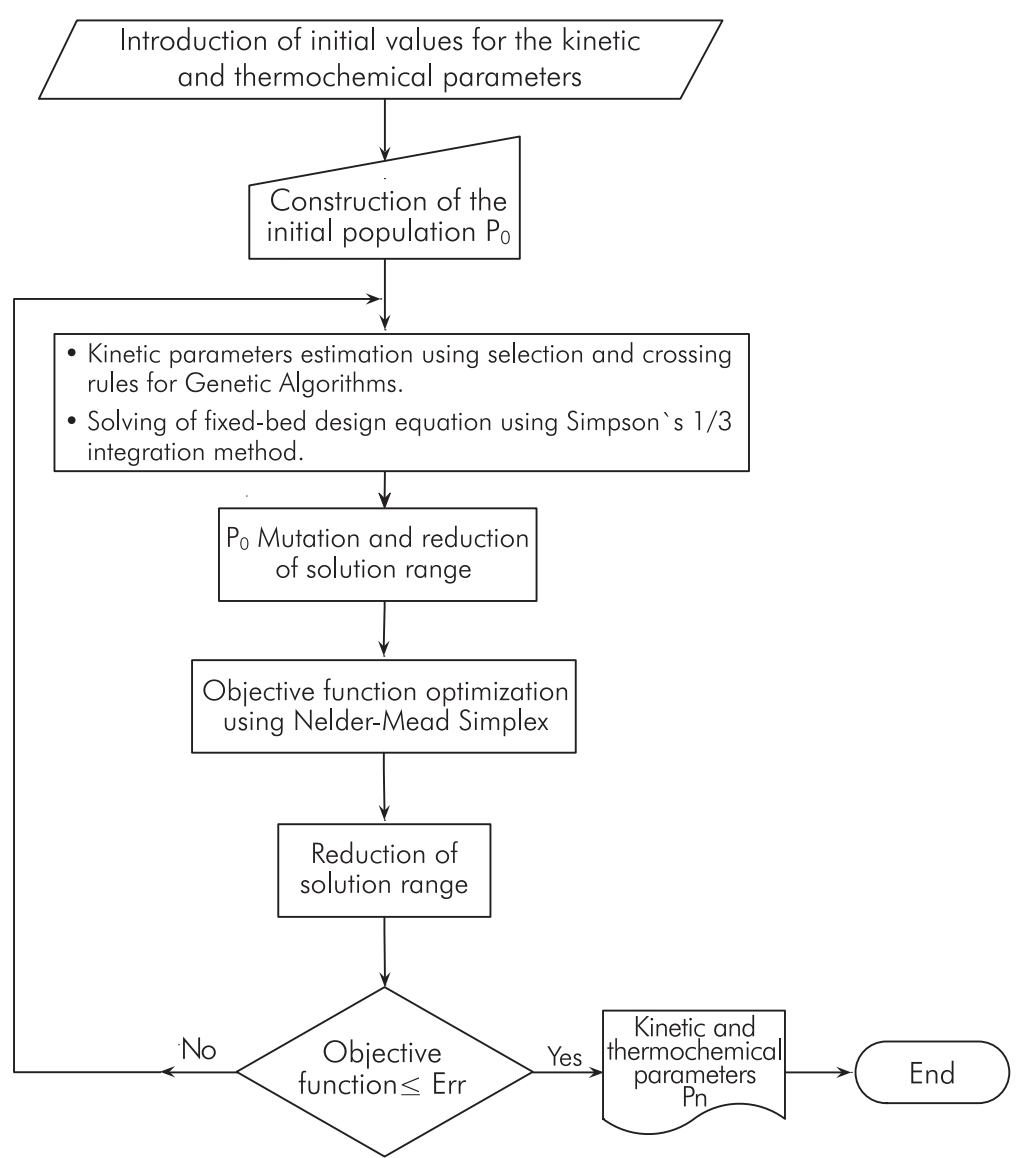

Figure 1. Optimization strategy for the thermochemical parameters estimation, using GAs as implemented in Matlab optimtool. 


\section{RESULTS AND DISCUSSION}

\section{Catalytic Evaluation}

Experimental results are shown in Table 4, corresponding to the experimental design reactions presented in Table 1. It can be observed that, as expected, HDS and HYD conversion levels depend on both reactant concentration and on temperature level. Some trends could be easily observed in Table 4 . For better illustration, some of these trends were plotted in Figure $2 a$ and $2 b$ In Figure 2a for example, it could be observed that the HYD conversion is inhibited with the increase in $2 \mathrm{MT}$ concentration. In contrast, in Table 4, HDS conversion variations with increasing olefins concentration were less important. This could be an indicative that sulfur molecules are competitively absorbed with olefins on the HYD sites. In some way this observation could support the use of only one site for HYD and HDS in our kinetic model. Regarding selectivity, in Table 4 it could be observed that at the lowest 2MT concentration (1 wt.\%) HDS conversion was higher than the HYD one, however at the medium and higher concentration levels (1.5 and 2 wt.\%) the inverse trend was observed. Thus, with increasing 2MT concentration, the HDS/HYD ratio was reduced. In contrast, by increasing the olefin content, the HDS/HYD ratio was increased. Thus, selectivity depends strongly on the reactant concentrations. This observation could explain some contradictory results in the literature; for example, Vrinat (1983) observed that the HYD conversion was higher than the HDS, meanwhile other authors (Mey et al., 2004) observed the inverse trend.

The temperature influence is shown in Figure $2 b$ as expected there is an exponential dependence of both HYD and HDS conversion with temperature. This could be ascribed to the Arrhenius law, which says that the rate constant vary exponentially with temperature. This behavior was also observed by Li et al. (2009). They found the rate constant after a linearization of the Arrhenius equation through a variable conversion. At lower temperatures, HYD conversion is clearly higher than HDS, however this difference is attenuated with the increasing in temperature. It is known that HYD reactions are thermodynamically limited at high temperatures because of their exothermicity (Jongpatiwut et al., 2004).

\section{Kinetics Model}

Figures 3 and 4 show the predicted conversion by the model with respect to the experimental, for the HDS and HYD reactions respectively. Both figures give an idea of how close are the predicted values using the model with respect to the experimental data. It can be observed in both cases, that dispersion is considerably small, indicating a good prediction of the model. There is a better fit for HDS, for which the calculation of the overall error at the three different temperatures was

Table 4. Experimental conversions $\left(C_{i}\right)$ of HDS of $2 M T$ and HYD of TMP.

\begin{tabular}{|c|c|c|c|c|c|c|c|}
\hline \multirow{2}{*}{$\begin{array}{l}\text { TMP(wt.\%) } \rightarrow \\
2 M T(w t . \%) \downarrow\end{array}$} & \multicolumn{2}{|c|}{10} & \multicolumn{2}{|c|}{15} & \multicolumn{2}{|c|}{20} & \multirow{2}{*}{ Temperature $\left({ }^{\circ} \mathrm{C}\right)$} \\
\hline & $\% \mathrm{C}_{2 M T}$ & $\% C_{T M P}$ & $\% \mathrm{C}_{2 M T}$ & $\% C_{T M P}$ & $\% \mathrm{C}_{2 \mathrm{MT}}$ & $\% C_{T M P}$ & \\
\hline 1.0 & 58.8 & 59.3 & 60.8 & 52.3 & 60.2 & 47.1 & \multirow{3}{*}{250} \\
\hline 1.5 & 38.3 & 51.9 & 39.8 & 37.7 & 33.6 & 28.3 & \\
\hline 2.0 & 25.3 & 47.8 & 29.6 & 37.9 & 22.2 & 28.5 & \\
\hline 1.0 & 80.1 & 72.5 & 74.5 & 65.1 & 78.5 & 61.7 & \multirow{3}{*}{260} \\
\hline 1.5 & 54.2 & 65.5 & 53.3 & 47.2 & 52.3 & 40.1 & \\
\hline 2.0 & 40.3 & 61.9 & 45.3 & 50.3 & 34.7 & 38.5 & \\
\hline 1.0 & 89.5 & 84.1 & 88.2 & 78.2 & 90.4 & 74.6 & \multirow{3}{*}{260} \\
\hline 1.5 & 76.5 & 80.1 & 74.2 & 63.8 & 71.2 & 53.8 & \\
\hline 2.0 & 60.5 & 76.1 & 64.2 & 67.5 & 58.3 & 60.2 & \\
\hline
\end{tabular}

2MT: 2-methylthiophene concentration; TMP: 2,4,4-trimethylpentene concentration. 


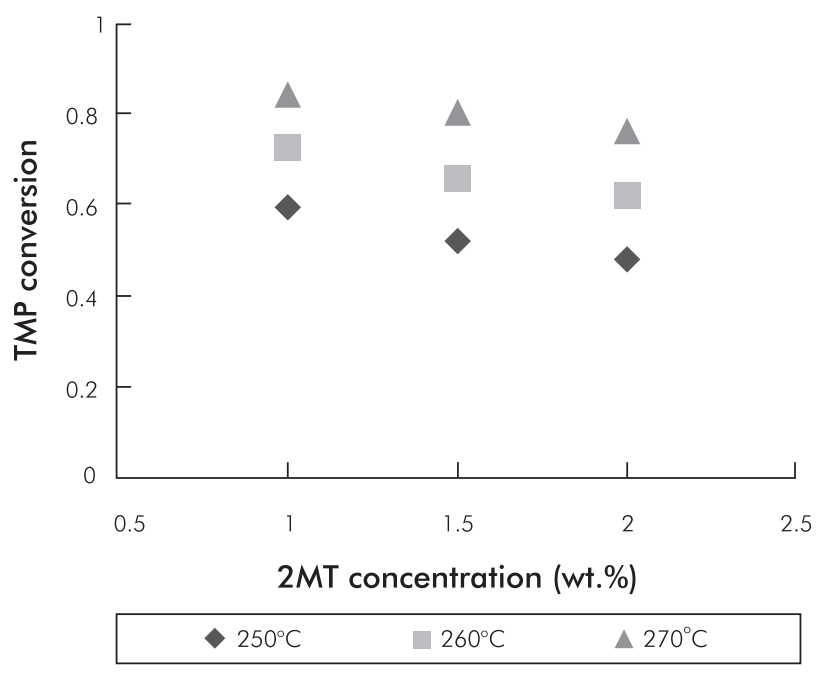

(a)

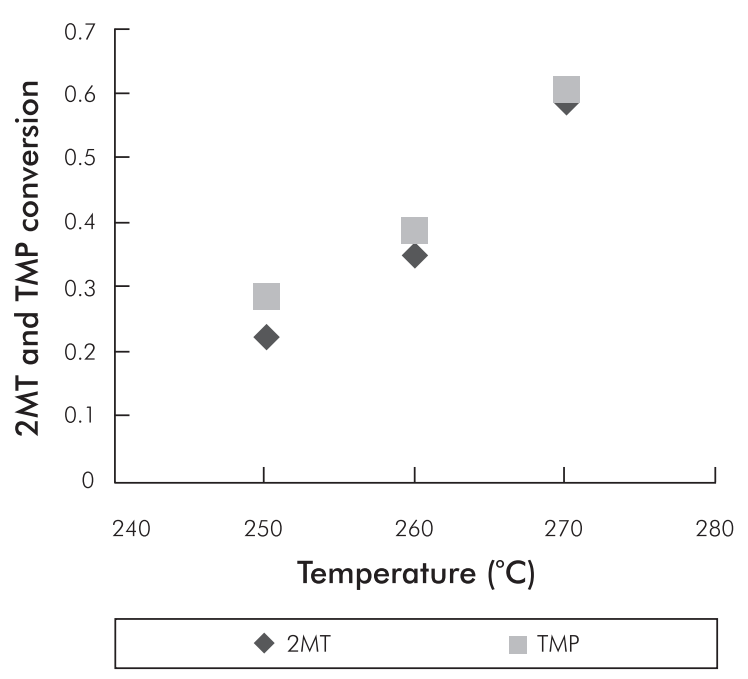

(b)

Figure 2. (a) TMP conversion as a function of $2 M T$ concentration at ( $\bullet$ $250^{\circ} \mathrm{C}$, (ם) $260^{\circ} \mathrm{C}$, and $(\mathbf{\Delta}) 270^{\circ} \mathrm{C}$. (b) conversions of $(\bullet) 2 \mathrm{MT}$ and $(\mathbf{\square})$ TMP depending on the temperature, for the reactions with a 2 wt.\% of 2MT and 20 wt. $\%$ of TMP.

only $6 \%$. On the other hand, the HYD presents a larger deviation regarding the model and leads to an overall error of $10 \%$. This could be explained, because certain reactions of isomerization and cracking were neglected in the modeling, as mentioned above. However, in spite of the certain level of dispersion in the predicted data, the trends of HDS and HYD with reactants concentration and temperature described above for the experimental data, are still observed in the predicted data.

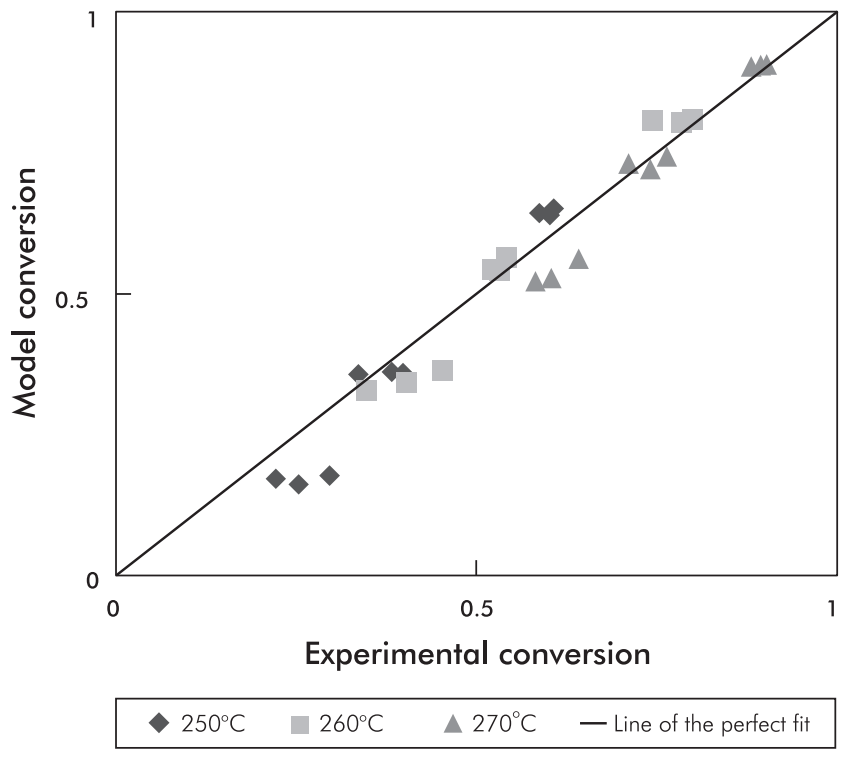

Figure 3. Dispersion of the experimental data. HDS conversion calculated by the GA simulations versus the HDS experimental conversion.

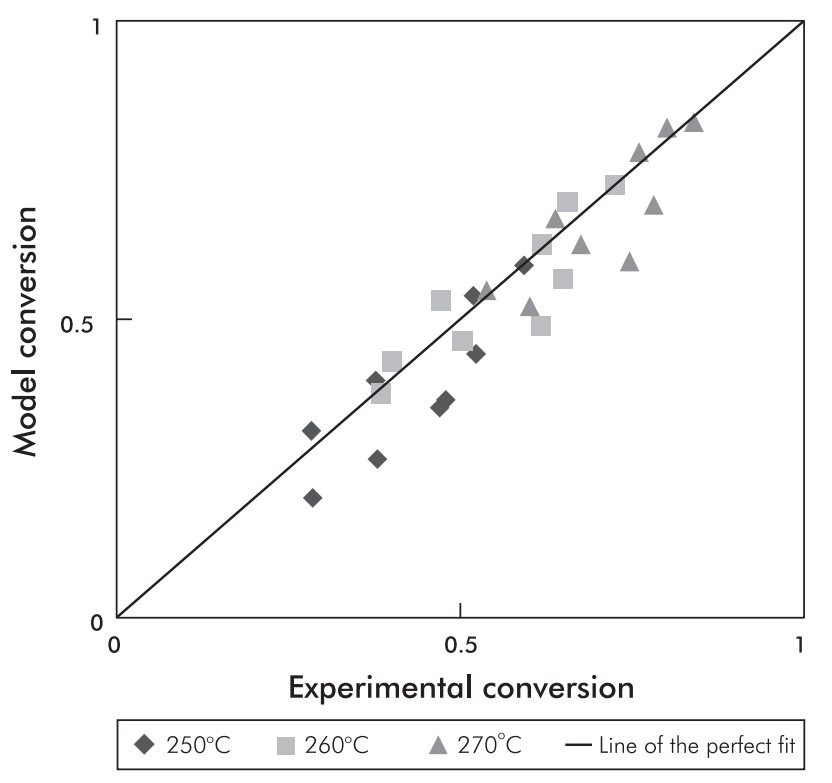

Figure 4. Dispersion of the experimental data; HYD conversion calculated by the GA simulations versus the HYD experimental conversion.

Figure 5a shows the objective function minimization evolution using GAs. The error percentage decreases as long as this becomes smaller. As Figure 5a shows, GAs were initially performed for finding global minimum. Thereafter (as shown in Figure 5b), it must be noted that values obtained through GAs were substantially refined 
using the Nelder-Mead Simplex method. It is possible to observe that at these conditions the calculation converges rapidly with less than 800 iterations. Results shown in Figures 3 and 4, along with the calculated overall error, indicate that model predictions are suitable, bearing in mind that the model was made on the basis of the existence of one type of active site, which may be far from the reality of intrinsic phenomenon that occurs in the reactions considered. Note that this approach is presented as a good alternative despite having been selected, because it facilitates the mathematical treatment and leads to a smaller number of experiments since it reduces the number of degrees of freedom. Other authors (Okamoto, Tomioka, Imanaka \& Teranishi, 1980; Kasztelan \& Guillaume, 1994) also used this simplification, and the deviations they obtained were similar to those presented in this work. Despite the error associated with the conceptual part of the mechanism, the reality is that the obtained model parameters lead to results that have a significantly small dispersion compared to experimental results seen in Figures 3 and 4. In this context, we believe that the mathematical modelling used for the application of genetic algorithms associated with the implementation of the Nelder-Mead Simplex method, contributed to this success.

The estimated thermodynamic properties and frequency factors are shown in Table 5. For the parameters estimations with the GAs, an average of 51 iterations was reached in approximately $165 \mathrm{~min}$. Additionally, there are some values reported in the literature and the confidence intervals for each parameter. As shown in Table 5, the confidence interval for each estimated parameter exhibits small values, and this indicates the validity of the approximation. Compared with previous studies (Lancheros \& Carreño, 2008) in which a Levenberg-Marquardt routine was performed to determine the kinetic parameters, the GAs show a rapid convergence, and also, estimations with best accuracy, comparing the activities calculated through these parameters (see Figures 3 and 4). The average errors obtained from the Levenberg-Marquardt routine were considerably high. The above-mentioned reasons lead us to prefer the GAs instead of the gradient based methodologies. Also, other authors (Vanrysselberghe et al., 1996) used successfully the Marquardt routine with 98 experiments, instead of 27 experiments required in our methodology.

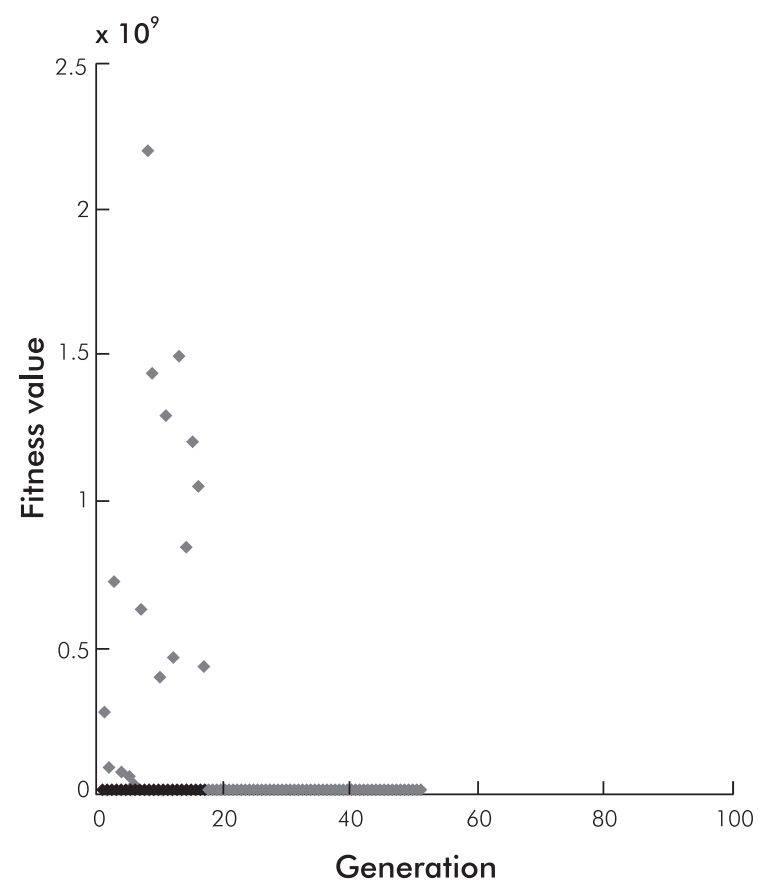

(a)

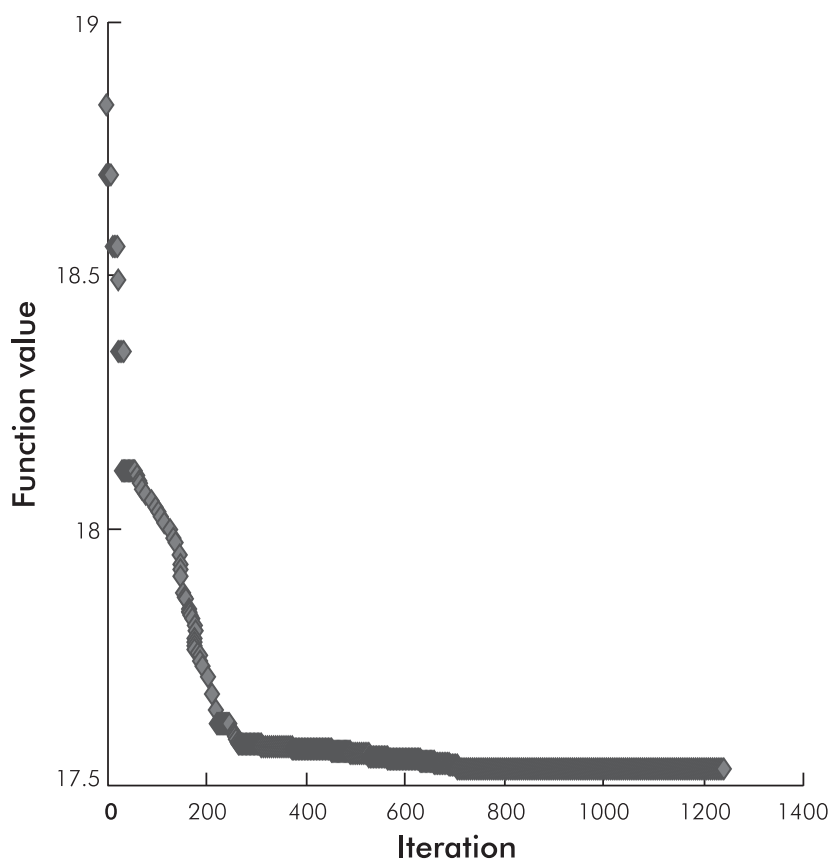

(b)

Figure 5. (a) objective function minimization in parameters determination using GAs Best: 18.1609, Mean: 77.2759.

(b) refinement using the Nelder-Mead simplex direct search, current function value: 17.5309. 
Table 5. Frequency factors and thermodynamic properties estimated from modelling.

\begin{tabular}{|c|c|c|c|}
\hline \multicolumn{2}{|c|}{ Estimated parameters } & Other authors* & Confidence intervals ( \pm ) $95 \%$ \\
\hline$A_{R}$ & $2333 \times 10^{-3}$ & & 0.01957 \\
\hline$A_{R S}$ & $22692 \times 10^{-3}$ & & 0.2117 \\
\hline $\mathrm{A}_{\mathrm{H}_{2} \mathrm{~S}}$ & $4.265 \times 10^{-3}$ & & $8.19 \times 10^{-5}$ \\
\hline $\mathrm{A}_{\mathrm{H}_{2}}$ & $5.825 \times 10^{2}$ & & 10.68 \\
\hline$A_{S}$ & $321.4 \times 10^{-3}$ & & 0.006561 \\
\hline$A_{H D S}$ & $5.746 \times 10^{3}$ & & 0.1851 \\
\hline$A_{H Y D}$ & $1.036 \times 10^{3}$ & & 1.008 \\
\hline$\Delta \mathrm{H}_{\mathrm{R}}(\mathrm{J} / \mathrm{mol})$ & $-4.189 \times 10^{3}$ & & 30.9 \\
\hline$\Delta \mathrm{H}_{\mathrm{RS}}(\mathrm{J} / \mathrm{mol})$ & $-2.054 \times 10^{4}$ & $-5.2 \times 10^{4}$ to $-1.9 \times 10^{4}$ & 34.46 \\
\hline$\Delta \mathrm{H}_{\mathrm{H}_{2} \mathrm{~S}}(\mathrm{~J} / \mathrm{mol})$ & $-1.1907 \times 10^{5}$ & & 513.9 \\
\hline$\Delta \mathrm{H}_{\mathrm{H}_{2}}(\mathrm{~J} / \mathrm{mol})$ & $-2.4998 \times 10^{4}$ & $-2.5 \times 10^{4}$ to $-1.4 \times 10^{5}$ & 505.4 \\
\hline$\Delta \mathrm{H}_{\mathrm{S}}(\mathrm{J} / \mathrm{mol})$ & $-2.2943 \times 10^{4}$ & & 505.5 \\
\hline $\mathrm{Ea}_{\mathrm{HDS}}(\mathrm{J} / \mathrm{mol})$ & $9.1253 \times 10^{4}$ & $6 \times 10^{4}$ to $1.63 \times 10^{5}$ & 0.1641 \\
\hline $\mathrm{Ea}_{\mathrm{HYD}}(\mathrm{J} / \mathrm{mol})$ & $5.9570 \times 10^{4}$ & $5.9 \times 10^{4}$ & 3.708 \\
\hline
\end{tabular}

*Vanrysselberghe \& Froment, 1996; Vanrysselberghe, Del Gall \& Froment, 1998.

The activation energies for HDS are higher compared with calculated values for HYD. This is expected accordingly to the observed behavior of these two reactions depending on the temperature, as shown in Figure 4. Moreover, a similar behavior is observed for the constants $K_{R}$ and $K_{R S}$. Adsorption constants for $\mathrm{H}_{2} \mathrm{~S}$ and $\mathrm{H}_{2}$ are significantly higher than the others, as observed in Table 4. This result is in good agreement with the possible difficulty that can produce a dissociative adsorption of $\mathrm{H}_{2} \mathrm{~S}$ and $\mathrm{H}_{2}$ on the catalyst surface, as discussed in previous works by Kaztelan and Guillaume (1995).

As observed in Figure 2, at equal conditions the activity of HDS is always lower than that for the HYD. This is remarkable at $250^{\circ} \mathrm{C}$, and the gap tends to disappear at higher temperatures. The above-mentioned behavior is in agreement with previous works (Vrinat, 1983). In this sense, the kinetic parameters determined in this work reproduce this important behavior and is described as a function of the temperature, in accordance with Arrhenius and Van't Hoff's laws.

\section{CONCLUSIONS}

- A kinetics model for the HDT of FCC gasoline that considers simultaneous HDS and HYD reactions was obtained. Despite considering only one active site for the competitive adsorption of reactants, it leads to a close prediction of the experimental results. Thus, it was possible to determine kinetic and thermodynamic parameters such as activation energies, adsorption heats and frequency factors with a fairly accurate approximation.

- It is remarkable that the activation energy of the HDS is higher than the calculated for HYD, and this behavior was experimentally observed. Additionally, the improvement of this kinetics would lead to a better understanding of the HDS/HYD selectivity, a very important relation in the FCC gasoline desulfurization.

- The mathematical strategy developed in this work, based on the application of genetic algorithms asso- 
ciated with the Nelder-Mead Simplex optimization method, proved to be an adequate strategy for predicting parameters when the number of experiments is relatively low. Using the methodology proposed in this article, it is possible to develop more rigorous kinetic models, which could include other types of active sites, close HDS conditions and reactions of interest in the HDT, leading to a better modeling of the catalytic system.

\section{ACKNOWLEDGEMENTS}

This work was possible thanks to funding from the Vicerrectoría de Investigación y Extensión-Universidad Industrial de Santander- through Project 5462. This article is dedicated posthumously to Professor Aristóbulo Centeno from UIS.

\section{REFERENCES}

Abassi, R. \& Fatemi, S. (2009). Mathematical modelling of gas oil HDS and optimization of operational conditions in Trickle-Bed reactor by genetic algorithm. Int. J. Chem. Reactor Eng., 7(1), 1542-6580.

Brunet, S., Mey, D., Pérot, G., Bouchyb, C. \& Diehlb, F. (2005). On the hydrodesulfurization of FCC gasoline: a review. Appl. Catal. A, 278(2), 143-172.

Daudin, A., Perot, G., Brunet, S., Raybaund, P. \& Bounchy, C. (2007). Transformation of a model FCC gasoline olefin over transition monometallic sulfide catalysts. J. Catal., 248(1), 111-119.

Daudin, A., Lamic, A., Perot, G., Brunet, S., Raybaund, P. \& Bounchy, C. (2008). Microkinetic interpretation of HDS/ HYDO selectivity of the transformation of a model FCC gasoline over transition metal sulfides. Catal. Today, 130(1), 221-230.

Edgar, T. F., Himmelblau, D. M. \& Lasdon, L. S. (2001). Optimization of chemical processes. Pennsylvania: Mc Graw Hill.

Elliott, L., Ingham, D. B., Kyne, A. G., Mera, N. S., Pourkashanian, M. \& Wilson, CW. (2004). Genetic algorithms for optimisation of chemical kinetics reaction mechanism. Prog. Energy Combust. Sci., 30(3), 297-328.

Farooji, N. R., Vatani, A. \& Mokhtari, S. (2010). Kinetic simulation of oxidative coupling of methane over perovskite catalyst by genetic algorithm: Mechanistic aspects. $J$. Nat. Gas. Chem., 19(4), 385-391.

Forrest, S. (1993). Genetic algorithms: Principles of natural selection applied to computation. Science, 261(5123), 872-878.

Jarullah, A, Mujtaba I. \& Wood, A. S. (2011). Kinetic parameter estimation and simulation of trickle-bed reactor for hydrodesulfurization of crude oil. Chem. Eng. Sci., 66:(5), 859-871.

Jongpatiwut, S., Li, Z., Resasco, D. E., Alvarez,W. E., Sughrue, E. L. \& Dodwell, G. W. (2004). Competitive hydrogenation of poly-aromatic hydrocarbons on sulfur-resistant bimetallic Pt-Pd catalyst. Appl. Catal. A, 262: 241-253.

Kasztelan, S. \& Guillaume, D. (1994). Inhibiting effect of hydrogen sulfide on toluene hydrogenation over a molybdenum disulfide/alumina catalyst. Ind. Eng. Chem. Res., 33(2), 203-210.

Kaufmann, T., Kaldor, A., Stuntz, G., Kerby, M. \& Ansell, L. (2000). Catalysis science and technology for cleaner transportation fuels. Appl. Catal. Today, 62(1), 77-90.

Le Page, J. F. (1987). Applied Heterogeneous Catalysis. Paris:Editions Technip.

Li, M., Li, H., Jiang, F., Chu, Y. \& Nie, H. (2009). Effect of surface characteristics of different alumina on metalsupport interaction and hydrodesulfurization activity. Fuel, 88(7), 1281-1285.

Martínez-González, J. L. (2001). Optimización y ajuste de parámetros mediante el Método Simplex (Nelder - Mead). la Reunión de Usuarios de EcosimPro, UNED, Madrid: EcosimPro.

Mey, D., Brunet, S., Canaff, C., Maugé, F., Bouchy, C. \& Diehl, F. (2004). HDS of a model FCC gasoline over a sulfided $\mathrm{CoMo} / \gamma-\mathrm{Al}_{2} \mathrm{O}_{3}$ catalyst: Effect of the addition of potassium. J. Catal., 227(2), 436-447.

Miller, J., Reagan, W., Kaduk, J., Marshall, C. \& Kropf, A. (2000). Selective hydrodesulfurization of FCC naphtha 
with supported $\mathrm{MoS}_{2}$ catalysts: The role of cobalt. $J$. Catal., 193(1), 123-131.

Montgomery, D. C. \& Runger, C. G. (2006). Probabilidad y estadística aplicadas a la ingeniería. 2nd Ed. México D.F: Limusa Wiley.

Morterra, C. \& Magnacca, G. (1996). A case of study: Surface chemistry and surface structure of catalytic aluminas, as studied by vibrational spectroscopy of adsorbed species. Catal. Today, 27(3-4), 497-532.

Navidi. W. (2006). Estadística para ingenieros y cientificos, México, D.F.: McGraw Hilll.

Lancheros, N. B. \& Carreño, S. A. (2008). Determinación de la cinética de las reacciones simultáneas de hidrodesulfuración del 2-metiltiofeno e hidrogenación del 2,4,4 trimetilpenteno sobre el catalizador $\mathrm{CoMo} / \gamma-\mathrm{Al}_{2} \mathrm{O}_{3}$. Tesis de pregrado, Ingeniería Química. UIS, Bucaramanga, Colombia, 51pp.

Okamoto, Y., Tomioka, H., Imanaka, T. \& Teranishi, S. (1980). Surface structure and catalytic activity of sulfided $\mathrm{CoMo} /$ $\mathrm{Al}_{2} \mathrm{O}_{3}$ catalysts: Hydrodesulfurization and hydrogenation activities. J. Catal., 66(1), 93-100.

Parijs, I. \& Froment, G. F. (1986). Kinetics of hydrodesulfurization on a $\mathrm{CoMo} / \gamma-\mathrm{Al}_{2} \mathrm{O}_{3}$ catalyst. 1. Kinetics of the hydrogenolysis of thiophene. Ind. Eng. Chem. Prod. Res. Dev, 25(3), 431-436.

Pérez-Martínez, D. J., Eloy, P., Gaigneaux, E. M., Giraldo, S. A. \& Centeno, A. (2010). Study of the selectivity in FCC naphtha hydrotreating by modifying the acid base balance of $\mathrm{CoMo} / \mathrm{Al}_{2} \mathrm{O}_{3}$ catalysts. Appl. Catal. A, 390(1-2), 59-70.

Ratnasamy, P. \& Sivasanker, S. (1980). Structural chemistry of Co-Mo-Alumnina catalysts. Catal. Rev. Sci. Eng., 22(3), 401-429.

Slomkiewicz, P. M. (2004). Determination of the LangmuirHinshelwood kinetic equation of synthesis of ethers. Appl. Catal. A, 269(1-2), 33-42.

Song, C. (2003). An overview of new approaches to deep desulfurization for ultra-clean gasoline, diesel fuel and jet fuel. Catal. Today, 86(1-4), 211-263.

Truhlar, D. G., Garrett, B. C. \& Klippenstein, S. J. (1996). Current status of transition-state theory. J. Phys. Chem., $100(31), 12771-12800$.
United States Environmental Protection Agency - EPA(2011). Standards for gasoline. United States. Accessed: May 12, 2013. Available in: <http://www.epa.gov/otaq/fuels/ gasolinefuels/index.htm>

Vanrysselberghe, V. \& Froment, G. F. (1996). Hydrodesulfurization of dibenzothiophene on a $\mathrm{CoMo} / \gamma-\mathrm{Al}_{2} \mathrm{O}_{3}$ catalyst: Reaction network and kinetics. Ind. Eng. Chem. Res, 35(10), 3311-3318.

Vanrysselberghe, V., Le Gall, R. \& Froment, G. F. (1998). Hydrodesulfurization of 4-methyldibenzothiophene and 4,6-dimethyldibenzothiophene on a $\mathrm{CoMo} / \gamma-\mathrm{Al}_{2} \mathrm{O}_{3}$ catalyst: Reaction network and kinetics. Ind. Eng. Chem. Res., 37: 1235-1242.

Vrinat, M. (1983). The kinetics of the hydrodesulfurization process: A review. Appl. Catal., 6(2), 137-158.

Vrinat, M., Laurenti, D. \& Geantet, C. (2012). Use of competitive kinetics for the understanding of deep hydrodesulfurization and sulfide catalysts behavior. Appl. Catal. B, 128: 3-9.

\section{AUTHORS}

Carlos-Mauricio Celis-Cornejo

Affiliation: Universidad Industrial de Santander.

Chemical Engineer, Ph. D. Graduate Student, Universidad Industrial de Santander.

e-mail: ransereg@hotmail.com

Gustavo-Alberto Granados-Zarta

Affiliation: Universidad Industrial de Santander.

Chemical Engineer, Universidad Industrial de Santander.

e-mail: gagz.07@gmail.com

\section{Carlos-Eduardo Bravo-Villarreal}

Affiliation: Universidad Industrial de Santander.

Chemical Engineer, Universidad Industrial de Santander.

e-mail: bravovillarreal1098@hotmail.com

\section{David de Jesús Pérez-Martínez}

Affiliation: ECOPETROL S.A. - Instituto Colombiano del Petróleo. Chemical Engineer, Ph. D. Universidad Industrial de Santander. e-mail: davidje.perez@ecopetrol.com.co

\section{Sonia A. Giraldo-Duarte}

Affiliation: Universidad Industrial de Santander.

Chemical Engineer, M. Sc. Universidad Industrial de Santander.

Docteur En Sciences Naturelles Appliquées, Universite Catholique

De Louvain.

e-mail: sgiraldo@uis.edu.co 


\section{NOTATION}

2MT 2-methylthiophene

4,6-DMDBT 4,6-dimethyldibenzothiophene

$A$

Arrhenius frequency factor, $\mathrm{L} \cdot \mathrm{mol}^{-1} \cdot \mathrm{s}^{-1}$

C Concentration of sites

C5s n-pentanes

$\mathrm{Ea} \quad$ Activation energy

$F_{A 0} \quad$ Molar flow, $\mathrm{mol} \cdot \mathrm{s}^{-1}$

FCC Fluid Catalytic Cracking

GAs Genetic Algorithms

HDS Hydrodesulfurization

HDT Hydrotreating

HYD Hydrogenation

$k \quad$ Rate constant, $\mathrm{L} \cdot \mathrm{mol}^{-1} \cdot \mathrm{s}^{-1}$

$K \quad$ Equilibrium constant

$P_{\mathrm{H}_{2}} \quad$ Hydrogen partial pressure, $\mathrm{Pa}$

$P_{\mathrm{H}_{2} \mathrm{~S}} \quad$ Hydrogen sulfide partial pressure, $\mathrm{Pa}$

$R \quad$ Gas constant

$r_{H D S} \quad$ Hydrodesulfurization reaction rate, $\mathrm{mol} \cdot \mathrm{s}^{-1}$

$r_{H Y D} \quad$ Hydrogenation reaction rate, $\mathrm{mol} \cdot \mathrm{s}^{-1}$

SSE Sum of Squared Errors

$T \quad$ Temperature, $\mathrm{K}$

2,4,4-trimethylpentene

TST Transition State Theory

W Catalyst weight, $\mathrm{kg}$

$x \quad$ Conversion

$\Delta H \quad$ Enthalpy change, $\mathrm{J} \cdot \mathrm{mol}^{-1}$ 


\section{SUFFIXES}

$\mathrm{H}_{2} \quad$ Hydrogen

$\mathrm{H}_{2} \mathrm{~S} \quad$ Hydrogen Sulfide

$M^{*} \quad$ Available active site

$\mathrm{MH} \quad$ Adsorbed hydrogen on an active site

$M R \quad$ Adsorbed $\mathrm{R}$ on an active site

MRS Adsorbed RS on an active site

MS Adsorbed sulfur on an active site

MSH Adsorbed SH on an active site

$R$ 2,4,4-trimethylpentene

$R S \quad$ 2-methylthiophene

$S \quad$ Sulfur 
